\title{
FIELD MEASUREMENT OF AEOLIAN SAND FLUX USING CERAMIC SAND FLUX SENSOR UD-101 AT A SAND DUNE
}

\author{
Keiko Udo ${ }^{1}$, Junaidi², Shin-ichi Aoki², Shota Mitsushio ${ }^{1}$, Shigeru Kato ${ }^{2}$, and Akira Mano ${ }^{1}$
}

\begin{abstract}
This study conducted field observations in terms of the number of blown sand impacts and wind velocity at an open ocean beach in Japan, in order to investigate characteristics of Charnock constant and aeolian sand transport flux over a sand dune slope. The number of blown-sand impacts was measured by aeolian sand flux sensor UD-101. As a result of the wind data analysis, the Charnock constant of a roughness length equation had a larger value over the slope compared to over a flat. Furthermore, as a result of the blown sand impact analysis, the aeolian flux over the slope tended to be larger than that over the flat. These fundamental findings in the field will become a great help for further investigation of the aeolian sand transport mechanisms.
\end{abstract}

Keywords: wind-blown sand; backshore; sediment transport

\section{INTRODUCTION}

Rising sea levels and increased storm intensities threaten beach and inland areas. The backshore plays an important role in protecting inland areas from coastal forces, serving as a site for beach recreation, and harboring rich ecosystems. In view of coastal engineering, backshore dunes have an important function of the coastal protection, and hence the dunes should be managed by considering its function. The backshore deforms mainly by aeolian (wind-driven) sand transport; however, most studies of beach processes have focused on foreshore and bar deformations caused by wave-driven sand transport.

Knowledge on aeolian sand transport has been accumulated mainly through wind tunnel experiment (e.g., Bagnold 1941; Owen 1964; Lettau and Lettau 1978); however, saltation mechanisms in the field (i.e., in unsteady winds) differ substantially from those in steady winds. Since the 1990s, high-frequency sampling instrumentation such as erodible mass sensors and high temporal resolution sediment traps have been employed to detect aeolian sand at frequencies of $1 \mathrm{~Hz}$ or greater, which has improved our understanding of the saltation systems in unsteady winds (Stockton and Gillette 1990; Jackson 1996; Stout and Zobeck 1997; Butterfield 1998; Davidson-Arnott et al. 2008).

The first author has been investigated the aeolian sand transport in the field using a piezoelectric sensor UD-101 (Chuo Kosoku) which can count the number of wind-blown sand at a high-temporal resolution of $1 \mathrm{~Hz}$ at a height (Kubota et al. 2006, 2007; Udo et al. 2008). Udo et al. (2008) carried out short-term field observations using UD-101 for several days in winter at the Hasaki Beach in Japan and demonstrated features of instantaneous aeolian transport over a flat bed under various meteorological conditions. In addition, Udo (2009) conducted long-term observations of the instantaneous transport over nine months and investigated seasonal characteristics of the aeolian transport.

Thus, the detailed aeolian transport has recently been reported; however, there are few studies on the transport over a slope. This study conducted field measurements of instantaneous aeolian flux at a sandy dune in order to investigate the aeolian transport characteristics over a slope.

\section{STUDY AREA}

Field measurement was conducted at the Nakatajima sand dune in central Japan on 21 February 2009 (Fig. 1). Waves and winds are relatively weak in summer except during typhoons, but strong in winter due to low pressure systems. The predominant wind direction in winter is from northwest to southeast, i.e., in the longshore direction. The dune has migrated eastward gradually and coastal forests downwind of the dune have been eroded seriously. Sand fences were installed in the upwind area of the dune in order to control the aeolian sand transport; however, the dune still continues to migrate.

The field measurement points were located at a dune foot (34³9'38.86’'N, 13744'32.92” E; point F) and a dune crest $\left(34^{\circ} 39^{\prime} 38.25^{\prime} \mathrm{N}, 137^{\circ} 44^{\prime} 36.18^{\prime} \mathrm{E}\right.$; point C) along the predominant wind direction, as shown in Fig. 2. Point $\mathrm{F}$ was located downwind of an approximate horizontal area, while point $\mathrm{C}$ was located downwind of a slope of 0.09; therefore, the sand transport over the horizontal area could be detected at point $\mathrm{F}$ and that over the slope could be detected at point $\mathrm{C}$.

\footnotetext{
${ }^{1}$ Disaster Control Research Center, Tohoku University, 6-6-11 Aoba, Sendai 980-8579, Japan

${ }^{2}$ Dept. of Arch. \& Civil Eng., Toyohashi University of Technology, Hibarigaoka 1-1, Tempaku cho, Toyohashi 441 8580, Japan
} 


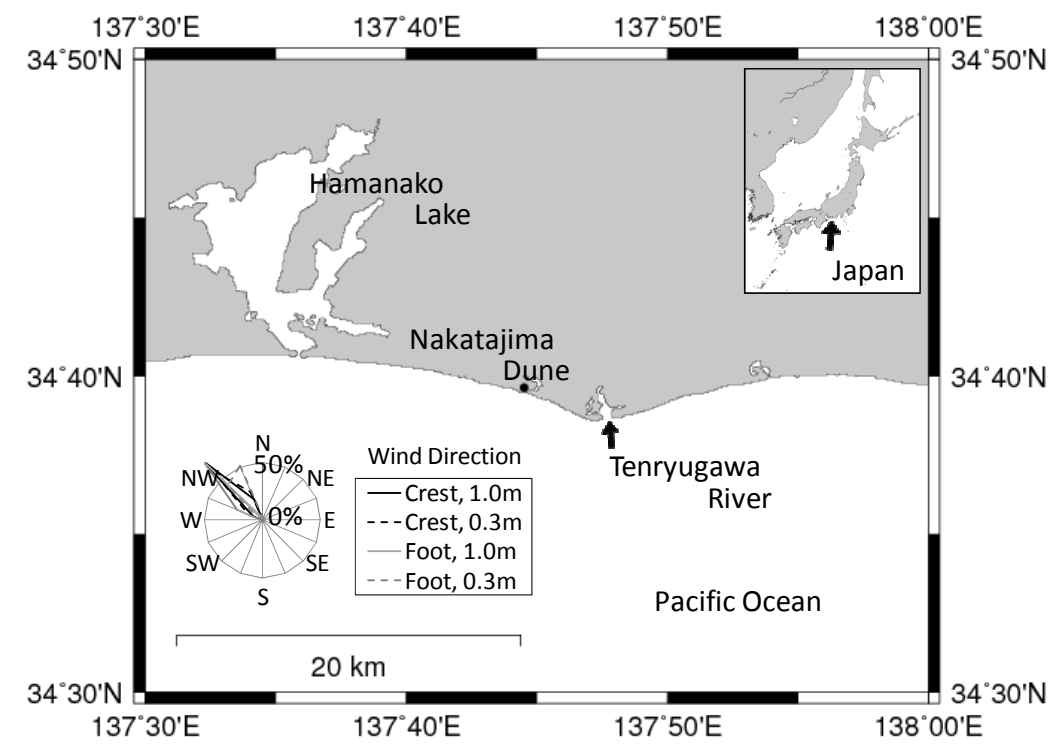

Figure 1. Location of the study site along with wind rose in 2004.

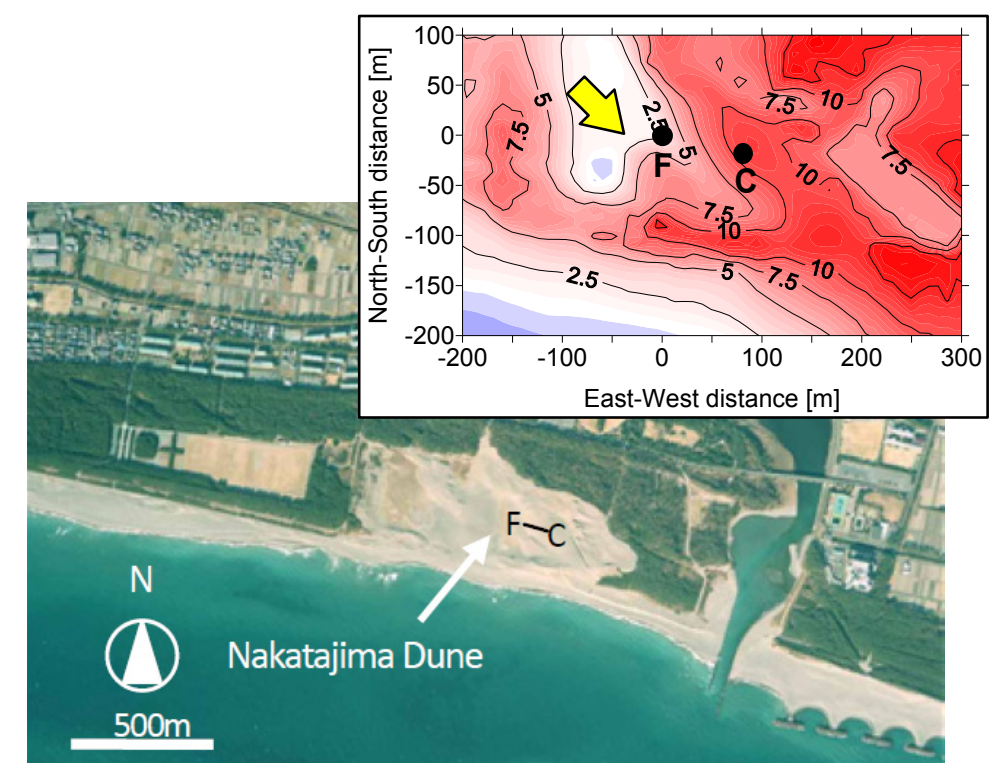

Figure 2. Aerial photograph and topography of the Nakatajima Dune. Field observations were conducted at points $F$ (dune foot) and $C$ (dune crest). Yellow arrow shows a predominant wind direction.

\section{METHODS}

Field data were obtained in terms of aeolian sand flux, wind velocity, and wind direction at points $\mathrm{F}$ and $\mathrm{C}$ (Fig. 3). The blown sand impact count as an index of the aeolian flux was measured at a height of $0.04 \mathrm{~m}$ above the ground $(z=0.04 \mathrm{~m})$ using a ceramic sand flux sensor UD-101. The sensor counts piezoelectric signals generated by collisions between blown sand grains and the sensor surface, using the same principle of acoustic impact detection as the Sensit (Stockton and Gillette 1990) and Safires (Baas 2004). Significant difference between the UD-101 and the others is that the UD-101 is unidirectional while both the Sensit and Safires are omnidirectional. The UD-101 should be placed in the same direction as the mean wind direction in the field; however, it has an advantage of counting only blown sand from the upwind side (Udo et al. 2008). The sensor used in this study had a diameter of $0.012 \mathrm{~m}$ and a length of $0.20 \mathrm{~m}$. The logger recorded the maximum 10,000 counts data at an interval 

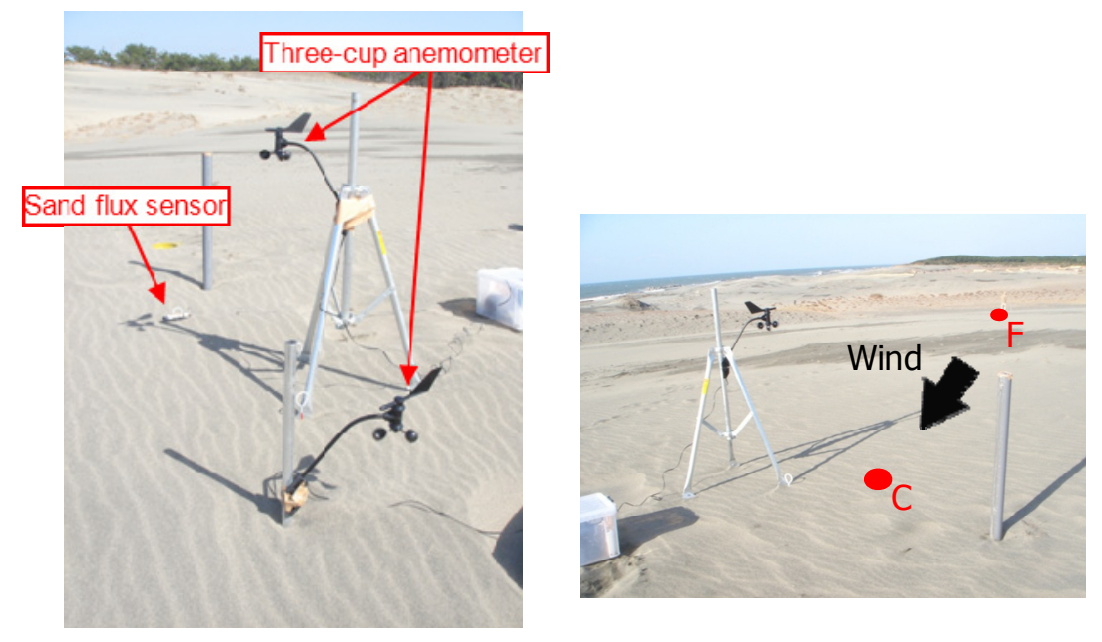

Figure 3. Photographs of the measurement points.

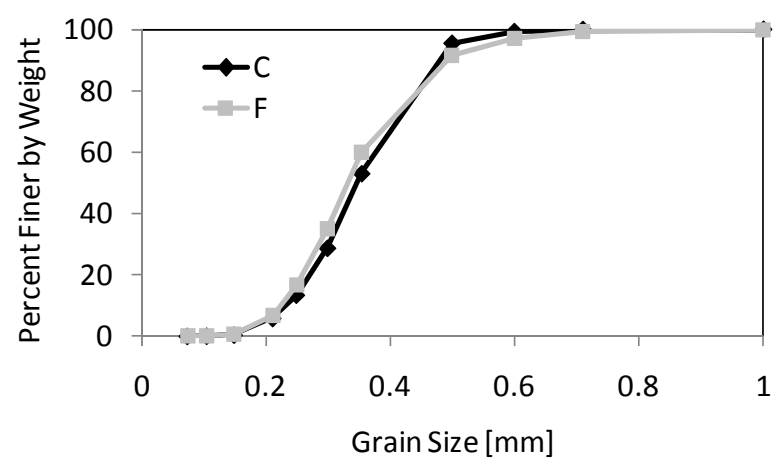

Figure 4. Cumulative sand size distributions at ground surface of points $F$ and $C$.

of $1 \mathrm{~s}$. The wind velocity and direction were measured at heights of $z=0.3 \mathrm{~m}$ and $1.0 \mathrm{~m}$ using threecup anemometers. The logger recorded 1-min mean wind velocity and direction.

The field data was analyzed statistically first; then, relationships between the wind velocities at $z=$ $0.3 \mathrm{~m}$ and $1.0 \mathrm{~m}$ were compared over the flat and the slope, respectively. Finally, the relationships between the wind forcing and the aeolian sand flux over the flat and the slope were compared to an existing equation derived from wind tunnel experiments.

\section{RESULTS AND DISCUSSION}

\section{Data descriptions}

Figure 4 shows grain size distributions of sand at ground surface of points $\mathrm{F}$ and $\mathrm{C}$, obtained using a stack of successively finer sieves. Median sand grain size $\left(D_{50}\right)$ was $0.33 \mathrm{~mm}$ at point $\mathrm{F}$ and $0.35 \mathrm{~mm}$ at point $\mathrm{C}$, respectively. These values are similar throughout a year.

Time series of the instantaneous impact count $(n), 1$-min mean wind velocity $\left(u_{\text {mean }}\right)$, and wind shear velocity $\left(u_{*}\right.$; which is related to wind forcing) at points $\mathrm{F}$ and $\mathrm{C}$ were shown in Fig. 5. Frequency distributions of $n, u_{\text {mean }}, u_{*}$, and wind direction $\left(d_{\text {mean }}\right)$ at points $\mathrm{F}$ and $\mathrm{C}$ were shown in Fig. $6 . d_{\text {mean }}$ is expressed clockwise from north, in positive degrees from 0 to 360 .

$u_{*}$ (and $z_{0}$ ) was calculated using $u_{\text {mean }}$ at heights of $z=0.3$ and $1.0 \mathrm{~m}$ using the logarithmic wind profile law expressed by

$$
u=\frac{u_{*}}{\kappa} \ln \left(z / z_{0}\right)
$$

where $u_{*}$ is the wind shear velocity, $\kappa$ is the von Karman constant $(=0.4), z$ is the measurement height of wind velocity $u$, and $z_{0}$ is a roughness length, respectively. 
(a)
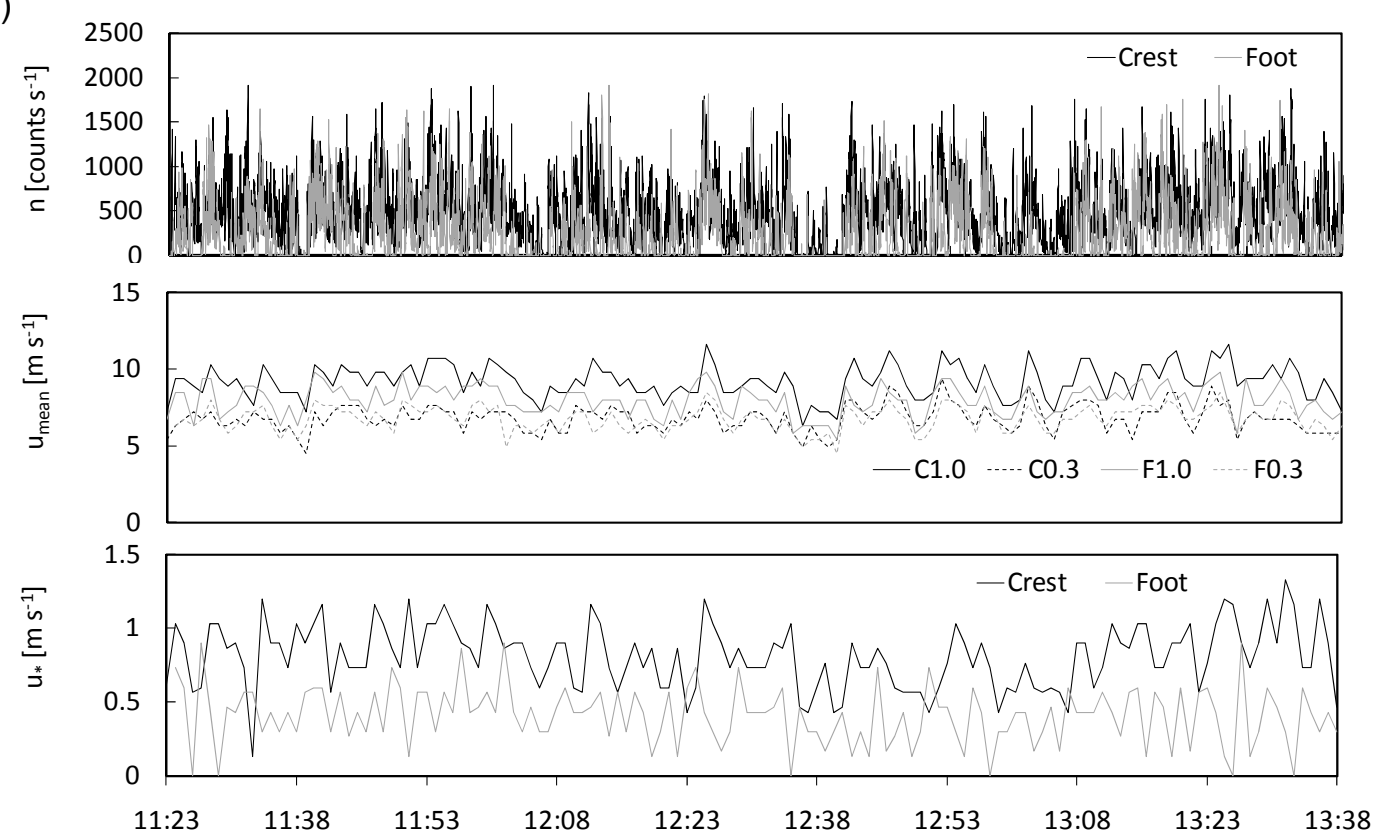

(b)

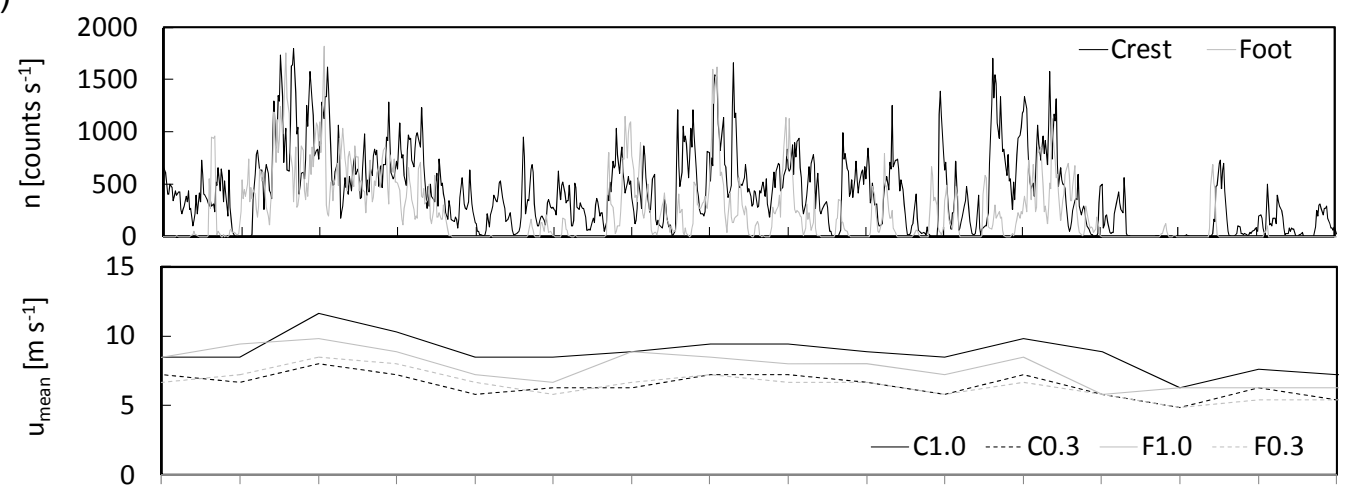

$\begin{array}{lllllllllllllllll}12: 23 & 12: 24 & 12: 25 & 12: 26 & 12: 27 & 12: 28 & 12: 29 & 12: 30 & 12: 31 & 12: 32 & 12: 33 & 12: 34 & 12: 35 & 12: 36 & 12: 37\end{array}$

Figure 5. Time-series of instantaneous sand flux $(n)$ and 1-min mean wind velocity $\left(u_{\text {mean }}\right)$ during the period $(a)$ for 135 minutes from 11:23 to $13: 38$ and $(b)$ for 15 minutes from 12:23 to 12:38. Wind shear velocity (u*) calculated using logarithmic wind profile law with $u_{\text {mean }}$ at points $F$ and $C$ was also shown in the figure (a).

It is demonstrated that both $n$ and $u_{\text {mean }}$ tended to be larger at point $\mathrm{C}$ compared to point $\mathrm{F}$ as shown in Fig. 6, though a direct instantaneous relationship of $n$ and $u$ could not be detected because of the relatively long temporal resolution of wind data (see Fig. 5). Frequency distributions of $d_{\text {mean }}$ were approximately equal at all measurement points of wind and ranged from west-northwest to northnorthwest, but the frequency distribution at $z=0.3 \mathrm{~m}$ at point $\mathrm{F}$ shows slight clockwise shift compared to the other distributions. This is likely to be caused by three dimensionality of dune topography.

\section{Wind forcing over flat and slope}

As shown in Fig. 6a and 6c, the peak frequencies of point $\mathrm{F}$ were 0.27 at $n=50$ counts $\mathrm{s}^{-1}$ and 0.55 at $u_{*}=0.7 \mathrm{~m} \mathrm{~s}^{-1}$; and those of point $\mathrm{C}$ were 0.12 and 0.11 at $n=50$ and 350 counts $\mathrm{s}^{-1}$, respectively, and 0.24 and 0.26 at $u_{*}=0.7$ and $1.1 \mathrm{~m} \mathrm{~s}^{-1}$, respectively. The frequency distributions of $n$ and $u *$ had a bimodal frequency distribution at point $\mathrm{C}$ but a unimodal distribution at point $\mathrm{F}$.

Next, $u_{*}$ was calculated with $u_{\text {mean }}$ at a height of $z=0.3 \mathrm{~m}$ or $1.0 \mathrm{~m}$ using equation (1) and Charnock (1955) model. Existing studies reported that the logarithmic wind profile law with the Charnock model can be applied in wind tunnel experiments and fields. The Charnock model is given by 
(a)

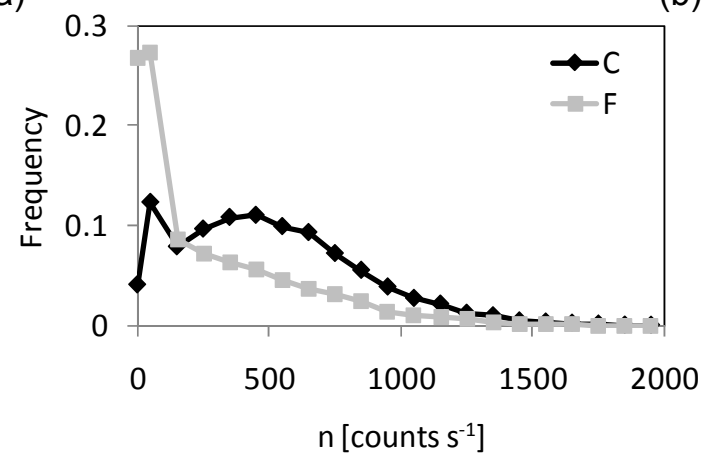

(b)

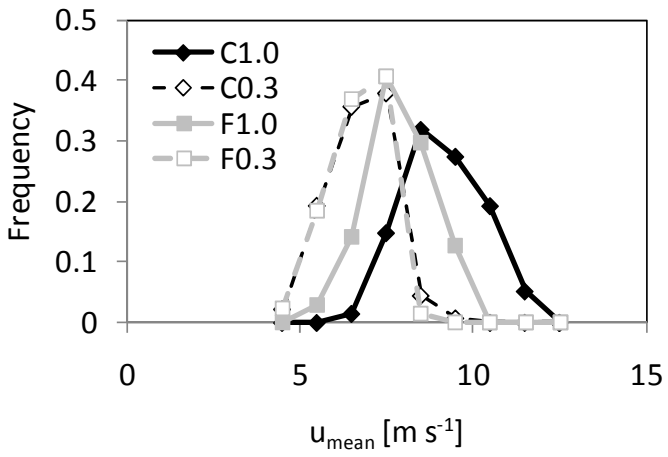

(d)

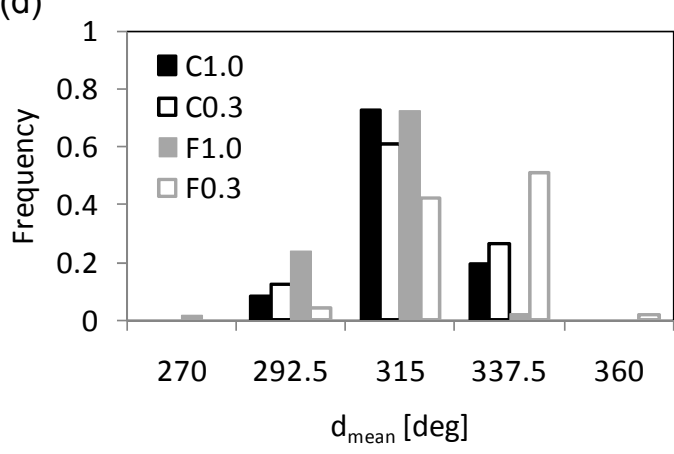

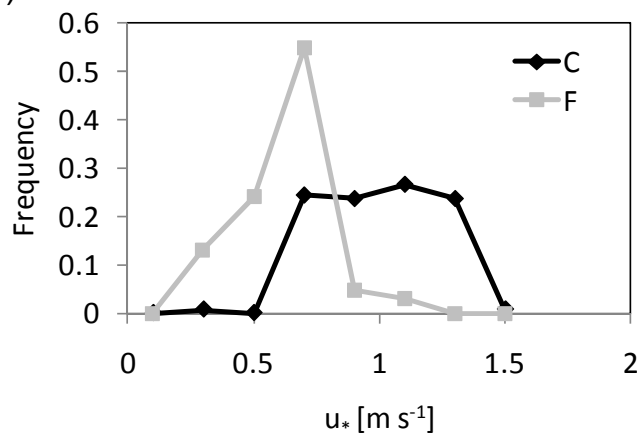

(c) $u_{*}$, and (d) mean wind direction ( $\left.d_{\text {mean }}\right)$ at points $F$ and

Fig

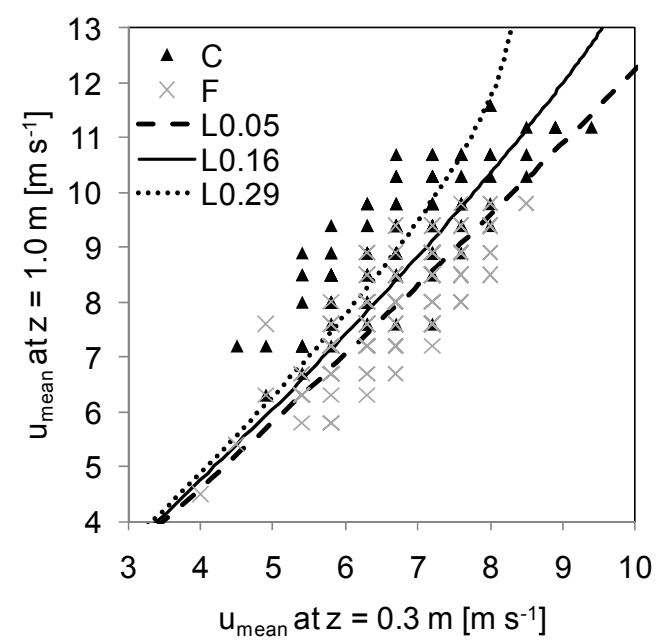

Figure 7. Relationships between $u_{\text {mean }}$ at $z=0.3 \mathrm{~m}$ and $1.0 \mathrm{~m}$ at points $F$ and $C$ with a curve from the logarithmic wind profile law. L0.05, L0.16, and L0.29 indicate relationships calculated from equation (1) and (2) with $c_{0}=0.05,0.16$, and 0.29 , respectively.

$$
z_{0}=c_{0} \frac{u_{*}^{2}}{2 g}
$$

where $g$ is the gravitational acceleration. $c_{0}$ is Charnock constant, for which Raupach (1991) gave 0.02 for wind tunnel experiments and 0.16 for beaches. Sherman and Farrell (2008) demonstrated that the 
maximum $c_{0}$ obtained from the existing results of several beaches was 0.24 and that the Raupach (1991) model was applicable in the fields.

The relationships between $u_{\text {mean }}$ at $z=0.3$ and $1.0 \mathrm{~m}$ for points $\mathrm{F}$ and $\mathrm{C}$ were compared to curves of those obtained from equations (1) and (2) for various $c_{0}$. As shown in Fig. 7, plots at point $\mathrm{F}$ scattered around the logarithmic law curve of $c_{0}=0.05$ and those at point $\mathrm{C}$ scattered around the curve of $c_{0}=0.29$, indicating that the law with the Charnock constant could be applied to the profile at the measurement points; these values are similar to values at a range of 0.01 to 0.24 in fields (Sherman and Farrell 2008). $c_{0}$ at point $\mathrm{C}$ was six times as large as that at point $\mathrm{F}$. This could indicate that $c_{0}$ over slope was larger than that over flat.

\section{Aeolian sand flux over flat and slope}

Figure 8 shows the relationships between $u_{\text {mean }}$ and 1-min mean $n\left(n_{\text {mean }}\right)$ and between $u *$ and $n_{\text {mean }}$ at points $\mathrm{F}$ and C. $u_{*}$ were calculated from two methods using (i) equations (1) and (2) with $u_{\text {mean }}$ at a height of $z=0.3 \mathrm{~m}$ or $1.0 \mathrm{~m}$ (see Fig. 8c-8f) and (ii) equation (1) with $u_{\text {mean }}$ at heights of $z=0.3 \mathrm{~m}$ and $1.0 \mathrm{~m}$ (see Fig. $8 \mathrm{~g}$ ). A curve of the relationship between $u_{*}$ and $n_{\text {mean }}$ in the figure obtained from an existing equation of Kawamura (1964):

$$
\begin{gathered}
q(z)=G_{0}\left[\lambda\left\{2 \sqrt{2} K_{0}(\xi)-2 \sqrt{2} \beta \sqrt{\frac{h_{0}}{g}} \xi K_{1}(\xi)\right\}+\frac{1}{\sqrt{2}} \frac{c \beta \sqrt{0.75 h_{0}}}{g} \xi^{2}\left\{K_{0}(\xi)+K_{2}(\xi)\right\}\right] \\
\xi=\sqrt{2 z / h_{0}} \quad \lambda=u_{1} / \sqrt{2 g h_{0}} \quad \beta=3 \pi \mu d / m \quad \int_{0}^{\infty} h f(h) d h=h_{0}
\end{gathered}
$$

where $c$ is a coefficient, $\lambda$ is a coefficient depending on the ejection angle, $h_{0}$ is the average saltation height, $u_{1}$ is the average horizontal velocity component of saltating grains, $\mu$ is the coefficient of viscosity, $m$ is the mass of a sand grain, and $K_{0}, K_{1}$, and $K_{2}$ are the modified Bessel functions of the second kind, zero, first, and second order, respectively. The coefficients were given by the values calculated using equations of Hotta et al. (2006). $G_{0}$ is the sand mass flux being entrained from sand surface $\left(\mathrm{kg} \mathrm{m}^{-2} \mathrm{~s}^{-1}\right)$ and given empirically by

$$
G_{0}=42.8 \rho\left(u_{*}-u_{*_{t}}\right)
$$

where $\rho$ is the air density and $u_{*_{t}}$ is the threshold wind shear velocity. $u_{*_{t}}$ is estimated from Bagnold's (1941) equation:

$$
u_{*_{t}}=A \sqrt{\frac{\rho_{s}-\rho}{\rho} g d}
$$

Figures $8 \mathrm{c}$ and $8 \mathrm{~d}$ showed good agreements of the plots at point $\mathrm{C}$ with the curve of Kawamura (1964) but did not show agreements at point F. Here, $c_{0}$ was given by 0.16 instead of 0.05 for the plots at point $F$ because Raupach (1991) gave $c_{0}=0.16$ for flat beaches. The results shown in Fig. $8 \mathrm{e}$ and $8 \mathrm{f}$ demonstrated good agreements both at points $\mathrm{F}$ and $\mathrm{C}$. Comparison of these figures indicates that the plots calculated from equations (1) and (2) using $u_{\text {mean }}$ at a height of $z=1.0 \mathrm{~m}$ rather than $z=0.3 \mathrm{~m}$ agreed better with the Kawamura curve.

On the other hand, as shown in Figure 8g, plots of the relationships between $u_{*}$ and $n_{\text {mean }}$ calculated using equation (1) with $u_{\text {mean }}$ at heights of $z=0.3$ and $1.0 \mathrm{~m}$ scattered around the Kawamura (1964) curve for $u_{*}>0.5 \mathrm{~m} \mathrm{~s}^{-1} \mathrm{~m}$ both at points $\mathrm{F}$ and $\mathrm{C}$; however, plots for $u_{*}<0.5 \mathrm{~m} \mathrm{~s}^{-1}$ scattered above the curve especially at points $\mathrm{F}$.

These results demonstrated that the relationships between $u_{*}$ and $n_{\text {mean }}$ agreed better with the existing Kawamura equation when $u_{*}$ was calculated using both equation (1) and (2), though there are still unclear issues such as the applicability of the Charnock model. Further study is required to clear those issues.

\section{Time lag between instantaneous aeolian sand fluxes at dune foot and crest}

In order to investigate a spatial characteristic of instantaneous $n$, i.e. time lag between $n$ at points $\mathrm{F}$ and $\mathrm{C}\left(n_{\mathrm{F}}\right.$ and $n_{\mathrm{C}}$, respectively), $n_{\mathrm{F}}$ was plotted against $n_{\mathrm{C}}$ lagged behind by $d t=0$ to $30 \mathrm{~s}$ for 26 fractions of 5-min time series in the measurement period. Figure 9 exemplifies relationships between 
(a)

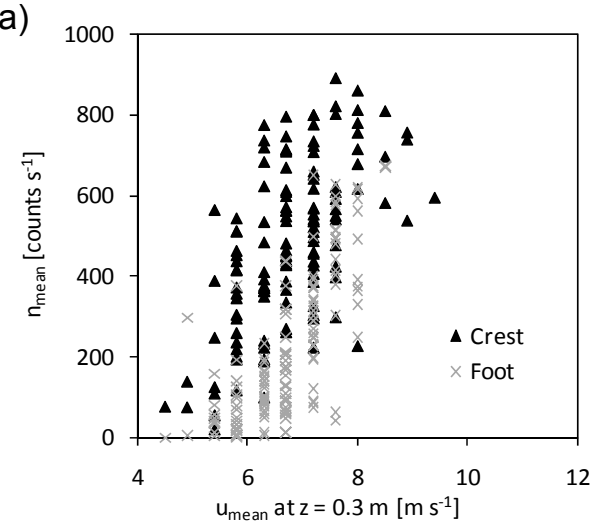

(c)

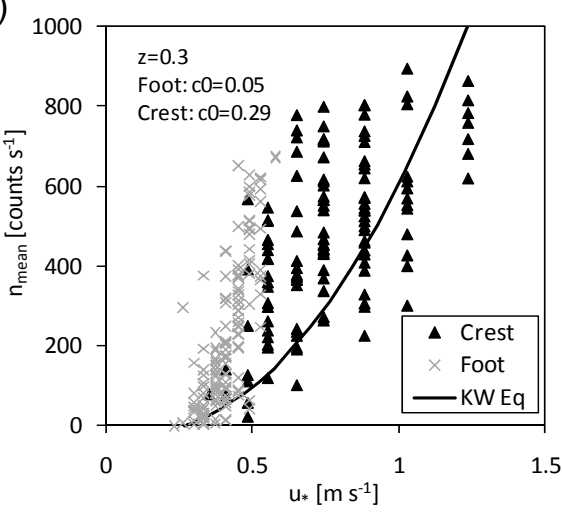

(e)

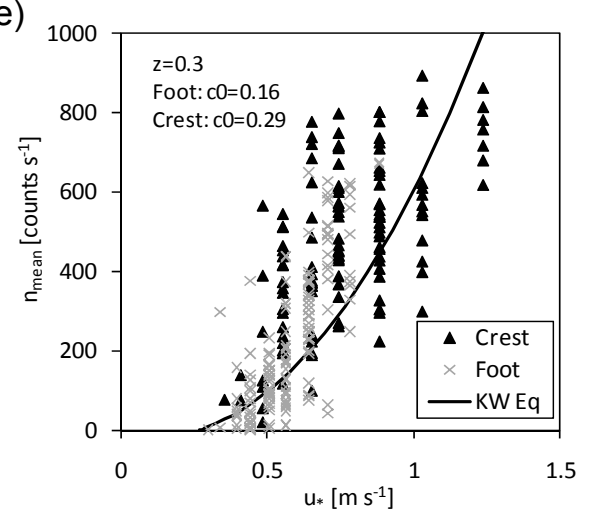

(g)

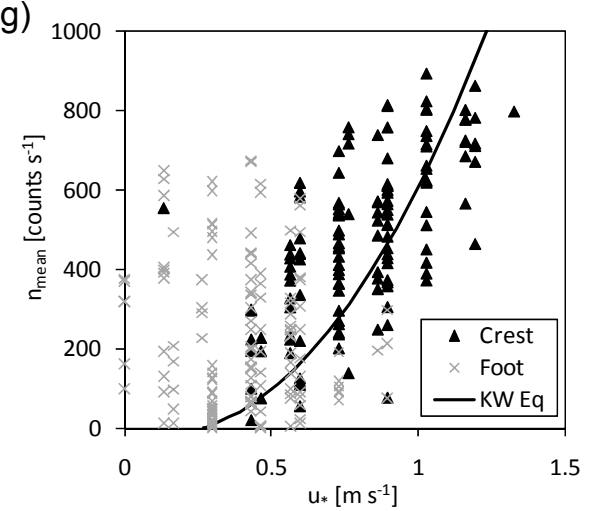

(b)

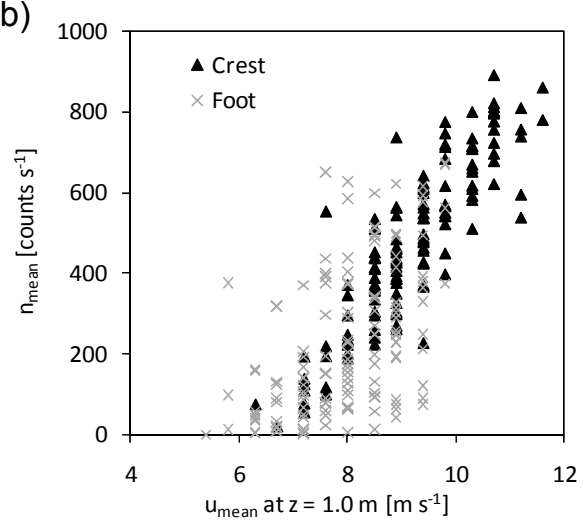

(d)

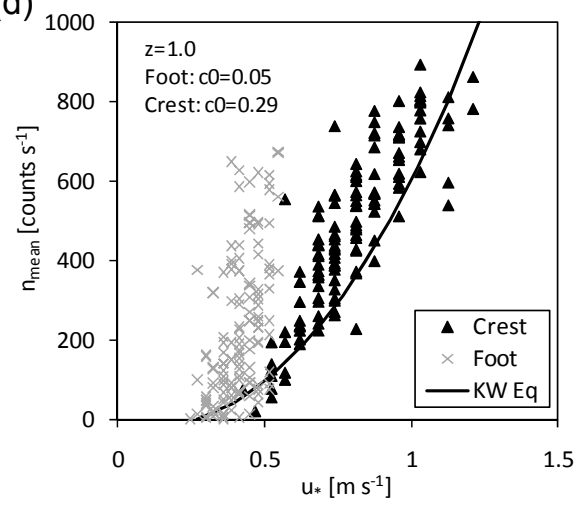

(f)

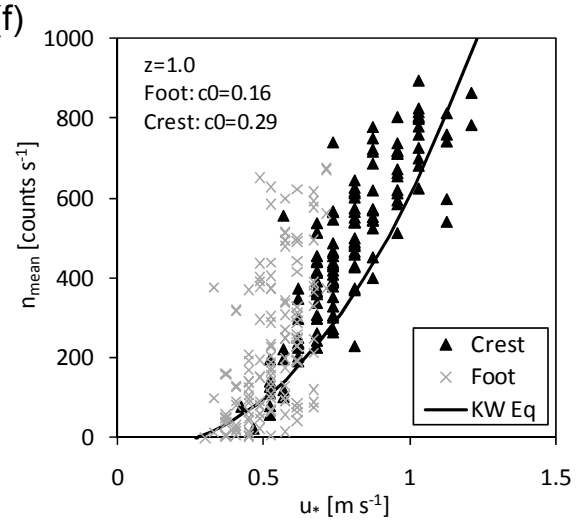

Figure 8. Relationships between $u_{\text {mean }}$ at (a) $z=0.3 \mathrm{~m}$ and (b) $1.0 \mathrm{~m}$ and $n_{\text {mean }}$, and $u_{*}$ and $n_{\text {mean }}$ at points $F$ and C. $u_{*}$ was calculated using equation (1) and (2) with $u_{\text {mean }}$ at a height of $z=0.3 \mathrm{~m}$ in (c) and (e), using equation (1) and (2) with $u_{\text {mean }}$ at a height of $z=1.0 \mathrm{~m}$ in (d) and (f), and using equation (1) with $u_{\text {mean }}$ at heights of $0.3 \mathrm{~m}$ and $1.0 \mathrm{~m}$ in (g). The line of KW Eq shows Kawamura's (1964) curve of the sand flux at $z=0.04 \mathrm{~m}$. 

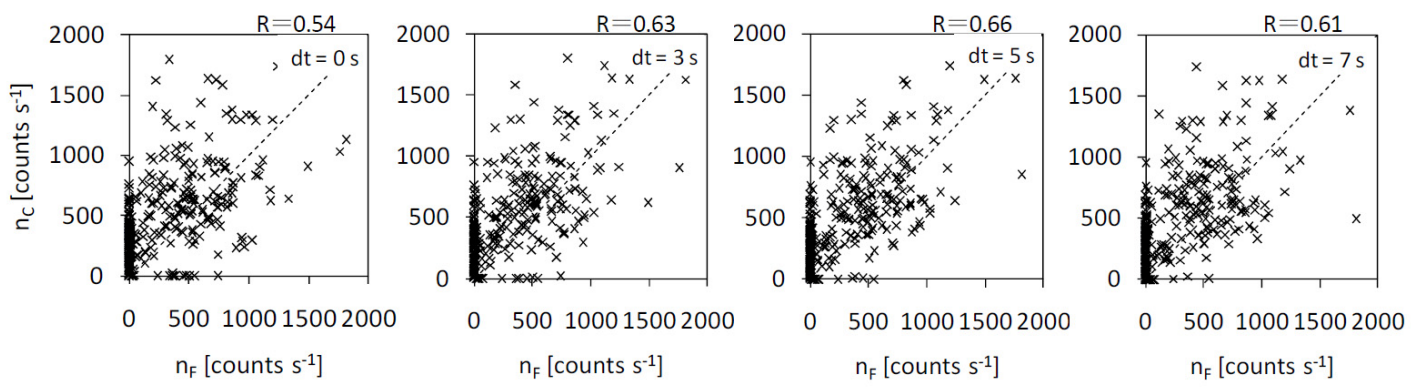

Figure 9. Relationships between instantaneous $n$ at points $F$ and $C$ ( $n_{\mathrm{F}}$ and $n_{\mathrm{C}}$, respectively) in a period of $12: 23$ to $12: 28(5 \mathrm{~min}) . n_{\mathrm{F}}$ was plotted with $n_{\mathrm{C}}$ lagged behind by $d t=0$ to $10 \mathrm{~s}$.

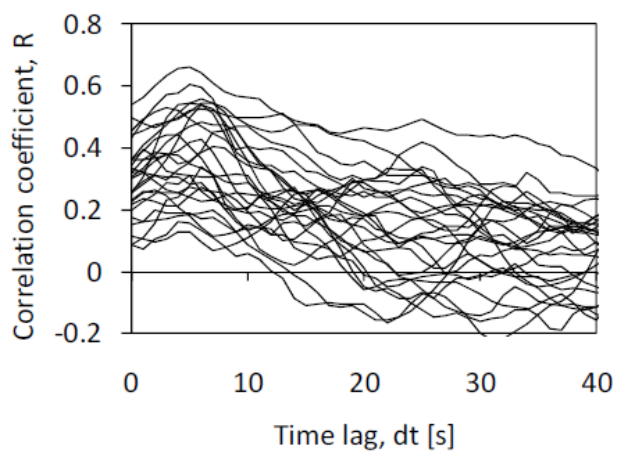

Figure 10. Relationships between $d t$ and the correlation coefficient $R$ for 26 fractions of 5-min time series.

$n_{\mathrm{F}}$ and $n_{\mathrm{C}}$ with correlation coefficients in a period of 12:23 to 12:28 (5 min). Figure 10 shows the relationships between $d t$ and $R$ for the 26 fractions.

Peaks of $R$ were appeared roughly at $d t=3$ to $6 \mathrm{~s}$. The mode of sand transport at $z=0.04 \mathrm{~m}$ (the measurement height of $n$ ) was expected to be saltation because 5-min mean wind velocity of the fractions were at a range of 7 to $10 \mathrm{~m} \mathrm{~s}^{-1}$; therefore, the maximum of $n$ could be considered to appear with the maximum of local wind velocity. Then, it is most likely that the local wind velocities at points $\mathrm{F}$ and $\mathrm{C}$ also had time lags of 3 to $6 \mathrm{~s}$. In other words, considering a distance between points $\mathrm{F}$ and $\mathrm{C}$ of $80 \mathrm{~m}$, it is supposed that the propagation velocity of a breath of wind (a variation in wind velocity) from upwind to downwind was 10 to $16 \mathrm{~m} \mathrm{~s}^{-1}$ larger than the mean wind velocity of 7 to $10 \mathrm{~m} \mathrm{~s}^{-1}$.

\section{CONCLUSIONS}

This study demonstrated the characteristics of the Charnock constant (i.e., a parameter of the roughness length) and the aeolian flux over the flat and the slope through the field observations in terms of the number of blown sand impacts and wind velocity. The Charnock constant calculated from the wind velocity data over the slope had a larger value compared to that over a slope; furthermore, the aeolian flux over the slope tended to be larger than that over the flat.

$u_{*}$ (i.e., an index of the wind forcing) were calculated from the two methods using (i) equations (1) and (2) with a wind velocity at a height and (ii) equation (1) with wind velocities at two different heights; and they were compared with $n$. The relationships between $u *$ and $n$ by the method (i) showed good agreements with the existing equation of Kawamura (1964) over both the flat and the slope, though the relationships by the method (ii) showed the larger scatter. These results indicated that $u *$ could be calculated reasonably by using the method (i) but also suggested that there are still unclear issues such as the applicability of the Charnock model.

Further study is required to clear those issues; however, these results obtained with the accurate and high-frequency sand flux sensor will become a great help for further investigation of the aeolian sand transport mechanisms. 


\section{ACKNOWLEDGMENTS}

The authors would like to thank members of Coastal Engineering Laboratory, Toyohashi University of Technology, Japan, for their support in the field observation. This study was partly supported by Special Coordination Funds for Promoting Science and Technology from the Japan Science and Technology Agency.

\section{REFERENCES}

Baas, A.C.W. 2004. Evaluation of saltation flux impact responders (Safires) for measuring instantaneous aeolian sand transport intensity, Geomorphology, 59, 99-118.

Bagnold, R. A. 1941. The Physics of Blown Sand and Desert Dunes, Methuen, London, 265 pp.

Butterfield, G.R. 1998. Traditional behaviour of saltation: wind tunnel observations of unsteady winds, Journal of Arid Environments, 39, 377-394.

Charnock, H. 1955. Wind stress on a water surface, The Quarterly Journal of the Royal Meteorological Society, 81, 639-640.

Davidson-Arnott, R.G.D., Yang, Y., Ollerhead, J., Hesp, P.A., and Walker, I.J. 2008. The effects of surface moisture on aeolian sediment transport threshold and mass flux on a beach, Earth Surface Processes and Landforms, 33, 55-74.

Hotta, S., Kubota, S., Nakamura, N., and Hosaka K. 2006. Wind tunnel study of vertical distribution of sand transport rate by wind, Proceedings of the 30th International Conference on Coastal Engineering, 2604-2616.

Jackson, D.W.T. 1996. A new, instantaneous aeolian sand trap for field use, Sedimentology, 43, 791796.

Kawamura, R. 1964. Study of sand movement by wind. In: Hydraulic Engineering Laboratory Technical Report, Berkeley, University of California, HEL-2-8, 99-108.

Kubota, S., Hosaka, K. and Oguri, Y. 2006. Development of wind blown sand measuring device used a ceramic piezo-electric sensor: Output of a ceramic piezo-electric sensor when sand grains hit (in Japanese), Rep. Res. Inst. Sci. Technol. Nihon Univ., 114, 93-103.

Kubota, S., Hosaka, K., and Tamura, T. 2007. Development of wind blown sand measuring device used a ceramic piezo-electric sensor: Part 2. Verification by a visual analysis using a high-speed camera (in Japanese), Rep. Res. Inst. Sci. Technol. Nihon Univ., 115, 141- 149.

Lettau, K. and Lettau, H.H. 1978. Experimental and micrometeorological field studies of dune migration, In Exploring the World's Driest Climates; Lettau, H. H. and Lettau, K. (eds.); Institute of Environmental Science Report 101, Center for Climatic Research, University of Wisconsin: Madison, UK, 110-147.

Owen, P. R. 1964. Saltation of uniform grains in air, Journal of Fluid Mechanics, 20, 225-242.

Raupach, M.R. 1991. Saltation layers, vegetation canopies and roughness lengths, Acta mechanica, [Supple] 1, 83-96.

Sherman, D.J. and Farrell, E.J. 2008. Aerodynamic roughness lengths over movable beds: Comparison of wind tunnel and field data, Journal of Geophysical Research, 113, F02S08, doi:10.1029/2007JF000784.

Stockton, P.H. and Gillette, D.A. 1990. Field measurement of the sheltering effect of vegetation on erodible land surfaces, Land degradation \& rehabilitation, 2, 77-85.

Stout, J.E. and Zobeck, T.M. 1997. Intermittent saltation, Sedimentology, 44, 959-970.

Udo, K., Kuriyama, Y., and Jackson, D.W.T. 2008. Observations of wind-blown sand under various meteorological conditions, Journal of Geophysical Research, 113, F04008, doi: 10.1029/2007JF000936.

Udo, K. 2009. New method for estimation of aeolian sand transport rate using ceramic sand flux sensor (UD-101), Sensors, 9, 9058-9072. 